\title{
Accounting for Accountability: A Discourse Analysis of Psychiatric Nurses' Experience of a Patient Suicide
}

\author{
Maggie Robertson*, Brodie Paterson, Billy Lauder, Rosemary Fenton and John Gavin
}

Department of Nursing and Midwifery, University of Stirling, Stirling FK9 4LA, Scotland, UK

\begin{abstract}
Whilst the experience of a patient suicide is likely to have a significant impact upon the nurses who had been providing care, little work has actually explored this experience in any depth. In this article we explore how two psychiatric nurses construct and orient to accountability when talking of their experiences of a patient suicide. Discourse analysis was used to explore particular phases that the nurses oriented to in their accounts: scene setting; risk assessment; attributing for the suicide. Findings highlight the different, sometimes contradictory, ways the nurses attended to interactional concerns relating to implicit accountability and potential inferences of blame. Analysis of the nurses' talk can make a valuable contribution to understanding the nature and the impact of 'accountability' in a mental health setting and so help nurses and other professionals gain an insight into their practice. The results from this study suggest that as a consequence of internalising fundamentally unrealisable expectations regarding suicide prevention, nurses can hold themselves to blame raising significant concerns around their needs in terms of support, which may not be recognised. This paper also makes a valuable contribution to our methodological understanding and the value of using discourse analysis in this setting.
\end{abstract}

Keywords: Patient suicide, accountability, psychiatric nurses, Potter and Edwards's discursive action model, discourse analysis.

\section{INTRODUCTION}

There were 843 deaths by suicide in Scotland in 2008 [1]. This equates to an age-standardised rate of 16.1 per 100,000 population compared to a European average of 7.5 per 100000 [2]. Psychiatric in-patients may however represent a particularly high-risk group. In an unpublished questionnaire survey (carried out by MR), patient suicide was the most common form of traumatic death identified as having been experienced by psychiatric nurses $(\mathrm{N}=180$ with a $55 \%$ response rate). The amount of free-text in the completed questionnaires showed that many respondents were acutely exercised by this topic. Twenty percent of respondents had enclosed details of their experiences relating to patient suicide in the form of notes and letters alongside their completed questionnaires. These free-text comments suggested that for a significant proportion of staff unresolved issues remained and most centred on personal and professional concerns and dissonance about (not) having done enough to prevent the event. These co-existed with feelings of self-blame and responsibility and/or perceptions of being blamed by colleagues or the service. Several of the respondents had indicated they had not received any support at the time and felt they would benefit from support even now, if it were on offer. Whilst not expecting that the experiences of nurses elsewhere would be any different, there remains surprisingly little literature exploring this aspect of a patient suicide.

*Address correspondence to this author at the Department of Nursing and Midwifery, University of Stirling, Stirling FK9 4LA, Scotland, UK;

Tel: 01786 466282; E-mail: maggie.robertson@stir.ac.uk
Midence et al. [3] carried out a survey via questionnaire to explore how nurses are affected by suicide. They found that the personal and professional impact patient suicide had on nurses was complex and significant. Major findings included the lack of emotional support from senior colleagues, the need for training, regular multidisciplinary meetings following a suicide and nursing staff's acceptance of suicide as the patient's personal choice. In another study Alexander et al. [4] sent a postal questionnaire to 315 consultant psychiatrists in Scotland (response rate of 78\%) to explore the impact of the most distressing suicide event the consultants had encountered. This study found that this event had a significant impact on consultant psychiatrists, with some psychiatrists reporting that they had contemplated taking early retirement after the experience. Acknowledging that different attitudes towards this event will pose particular difficulties for those who encounter it, this work shows that patient suicide is a legitimate occupational health concern. Alexander suggested psychiatrists needed to strike a balance between viewing suicides as fundamentally unavoidable and perceiving them to be largely predictable and thus preventable. If suicide is seen as unavoidable this may defend the profession from blame and at the same time question the value of therapeutic interventions. Conversely, if suicide is perceived to be largely preventable and predictable, this may foster a culture of blame and 'blame' may be self blame" [4]. Furthermore, activities such as risk assessment associated with suicide can be seen to create unrealistic expectations. The work by Paterson et al. [5] found that consistency of judgments about the risk of suicide was low, particularly amongst nurses. This work raises doubt over the validity of predictions of risk for imminent suicide and the role of such predictions in the assessment process. 
A study by Valente and Saunders [6] examined the literature to identify the support provided or recommended for nurses after a patient suicide. Whilst they found few studies, those that were identified reported that patient suicide could have a long-lasting psychological burden on the nurse, with clinical symptoms of grief predicting the future mental health outcomes of those involved. These authors make clear that nurses need to recognise their own grief to prevent and reduce self-blame and excess responsibility. Whilst the effects of suicide on staff are recognised, most of the current literature on suicide does not examine the psychological or emotional impact in any depth.

Although there may be a number of factors to address as to where responsibility for suicide may lie [7], the National Confidential Inquiry adopts the position that a significant number of suicides should be viewed as preventable. In $49 \%$ of the total cases of suicide across England and Wales the person had been in contact with services in the previous week, with $19 \%$ having contacted services in the 24 hours beforehand. Furthermore, $18 \%$ of total suicides carried out by in-patients were viewed as being the most preventable [8].

Whilst it has been recognised that most mental healthcare providers will experience a patient suicide in their career [9], how nurses experience or describe the impact of a patient suicide remains relatively under-explored. To explore in greater depth how evaluations, opinions and judgements surrounding patient suicide may be constructed, a systematic analysis of discourse is necessary. This paper examines extracts of talk from two nurses working in an acute psychiatric ward, who had found themselves involved in a fatal accident inquiry after the suicide of a female patient. The aim of the paper is to illuminate and explore how nurses' 'talk' of the event was organised and managed from a discursive perspective.

\section{METHODOLOGY}

A discourse analytic approach is most suited for this study since it allows for an illumination of the concerns that nurses might have without having to pre-define the issues [10]. As the analytic method is more concerned with the ways language is used (as opposed to simply what is said) sample size is not an issue for this study. Furthermore, as Schegloff [11] informs us, "talk-in-interaction' is seen to possess an internally grounded reality of its own". Thus, an interview approach was used to explore the experiences and perspectives of two nurses who had been on duty when a patient left the hospital grounds to 'complete' suicide. Given suicide is no longer an offence (at least in Britain) the use of the term 'committed' is considered archaic in the suicidology academic community. The term 'completed' is used here simply to highlight the attempt as being successfully executed. Using interviews to elicit participant's perspectives can enhance understanding of the impact that suicide may have had upon the nurses at the time as well as in the longer term [12].

Discourse analysis has been applied to a number of different social, psychological and health arenas for example, the construction of racism [13, 14]; occupatio-nal choice [15]; psychiatric medication [16]; shared decision-making in general practice $[17,18]$.
Underpinning all forms of discourse research is the view that discourse is regarded as social action. This involves an examination of how the relationship between the "world and the word' is addressed in talk [19] and how "language orders our perceptions and makes things happen" and "is used to construct and create social interaction and diverse social worlds" [20]. The discourse analytic approach taken comes from the field of discursive psychology and utilises Edwards and Potter's discursive action model (DAM) as both a theoretical framework and a method of analysis [21]. Within this approach, language use is regarded as varied, contradictory and used to perform particular social functions. Thus, any interaction is 'action-oriented'. In other words, people use language to do things, not least, to construct the social world and their place in it. People formulate accounts and descriptions to perform particular activities such as excusing or blaming; praising or criticising; accepting or refusing. Owing to the flexibility of language use the same event can be described or accounted for in a variety of ways depending on what the speaker or the account is being used to do, so variability is of particular interest to the analyst. The DAM model is especially suited to the present study as much of its theoretical underpinning concerns itself with the ways in which people account for things, here the ways in which the nurses formulate their experience in terms of addressing matters of professional responsibility and accountability.

Because of the reflexive nature of discourse analysis, all participants' talk is included in the analysis and the cultural background of the analyst should also be recognised as influential. As a result of sharing a similar background, knowing both participants and some of the staff referred to, the content of the interviews are regarded as having been jointly produced by the interviewer (MR) and the nurses. In other words, the nurses' accounts have oriented, both to what the interviewer has said as well as 'who' the interviewer is or represents, i.e. the interviewer cannot be viewed as if a neutral bystander, simply hearing a story. Such features are illuminated in the analysis.

In sum then, discourse analysis provides a means of critical engagement and offers an alternative and refreshing way to interpret how the social and psychological worlds are discursively formed. For this study, it has been possible to shed light upon some of the discursive strategies and activities deployed by the two nurses to deal with unspoken professional and personal concerns around agency and responsibility for events leading up to the news that a patient had completed suicide.

\section{METHODS}

\section{Participants and Data Collection}

Ethical approval was sought from the Tayside Research Ethics Committee. Although the criteria for ethical approval has since changed, at the time of the study it was deemed that approval was not required as participants were not patients and they worked for the NHS. However, the head of nursing services was informed of the study and he offered his support by allowing the researcher and the participants, time away from the ward to carry out the research. 


\section{Participants}

Having already indicated to the researcher (via an unpublished survey), that they would be keen to discuss their experiences further, two female Registered Mental Nurses from Tayside, who had worked together in the same acute psychiatric ward, and had experienced the same patient suicide four years earlier, were approached separately by MR and invited to participate.

Following detailed discussion relating to the nature of the study and their involvement in it, informed consent was verbally requested from, and given, by the two nurse participants. Both nurses were told they could leave the study at any time should they choose. They were also given a cooling off period and advised that if they wished to, they could ask for quotes to be removed. Although the participants were not asked to sign a consent form informed consent is crucial. MR was satisfied at the time that both nurses understood the aims of the research and were clear about the nature of their involvement and wanted to participate.

The participants were interviewed on separate occasions in 2001. There were no pre-determined questions because it was felt that the nurses should be given the opportunity to talk about their experiences in whichever way they chose. This also protected against making a priori assumptions about the data. The nurses were asked simply to 'tell their stories' of the event. The first interview (Emma) took place in the hospital and the other at the home of the nurse (Anna). The interview was audiotaped and transcribed verbatim. The names of the nurses and other identifiers have been changed or removed to preserve anonymity.

\section{Background to the Event}

The patient had been in hospital for several weeks. She was being nursed in a general psychiatry ward. Whilst it is not exactly clear, it appears that the patient had a recent history of psychosis, if not a diagnosis of schizophrenia.

There are several observation categories that are commonly practised within psychiatric care facilities. The medical and nursing team usually decide together upon the observation levels (although the medical team have the final say). These can range from general observations, where nurses do not have to have patients within sight at all times through to 'special' or 'one-to-one' observation levels. Patients who are viewed as being at risk of suicide tend to be on 'one-to-one' observation. The patient had 'ground parole', which meant that she could have time out of the ward without being accompanied by nursing staff. This was normal practice particularly for preparing patients for home. The patient was to be discharged home the next day.

Attending diversional activities is also part of a patient's care and the patient had gone to occupational therapy (OT) on the day of her suicide. It appears that whilst there she had become distressed. The occupational therapist had contacted the ward to inform the nursing staff of this and had advised that the patient would be returning to the ward. The patient left the therapy department and then left the hospital. Very soon after, she completed suicide by jumping from a bridge into a river.

\section{Data Analysis}

The recorded interviews were listened to twice before being transcribed by the author. In the interests of readability, and as a reflection of the general rule that text should never be transcribed in more detail than the purpose demands, a broad transcription with minimum detail was applied. Lines have been numbered; punctuation has been used minimally with '...' to indicate pauses in speech. When an utterance is cut off a colon is used to indicate this. Overlapping speech is contained in brackets.

The next stage required the transcripts to be re-read several times in order to 'render the familiar strange' [19] and to help with this, Potter and Wetherell suggest that the analyst should approach the data with a number of questions such as, "Why read the text in this way and what are the features that produce this reading?". Being familiar with other work from the field of discursive psychology was particularly helpful as the analyst was able recognize discursive features already described in other work.

We are interested in illuminating the ways the nurses' 'stories' are constructed to address concerns relating to professional accountability by countering imputations of blame and responsibility and providing themselves with rhetorical protection. Although there were a number of features of analytic interest in the nurses' accounts space does not permit a full discussion of every one so sequences of talk where the nurses orient to particularly sensitive areas of interactional concern are presented to provide analytic utility [22].

Analysis is not concerned with ontological concerns around blame: rather, the focus is on how orientation to accountability, blame and responsibility is discursively constructed. Speakers tend to orient to implicit problems when accounting for events [23]. Emma and Anna therefore "are motivated to produce accounts of their actions that will be seen as legitimate" [24] and are thus required to formulate a convincing account to show that the suicide should not be attributed to any 'actions or omissions' on their part. Not only do the nurses want to show they did their job well and that they are 'good' nurses, they will also want to show they are also decent people. They do this persuasively. First they do not 'just' dismiss the event as an unavoidable hazard of the job and second, they minimise their own stake or interest by not making direct claims of self-praise.

\section{Scene Setting}

The first thing to note is that Emma and Anna formulate what is recognisable as a classic account of the nature of the event and also their experience. Whilst it may seem that Emma and Anna paint a straightforward picture the accounts are not impartial, as first impressions may suggest. Often the apparently irrelevant detail works to provide veracity for the account $[19,25]$.

\section{Emma 1}

\section{Basically I'd just started up in (ward) which is}

12. an acute ... was an acute ... was an acute ward at the time and 13. there had been a lot of problems with staffing and things like 14. that. So in the morning I'd come in - I'd been running my own 
15. shift probably about two or three weeks em that was the first

16. acute experience I'd really had so I'd went in and there was

17. only myself and a ' $\mathrm{D}$ ' grade staff nurse on. Twenty-eight

18. patients, we'd a lot of people boarding out (cleared throat).

19. There was a lot of things going on basically. Although we'd just

20. restrained one patient and settled her down we'd managed to

21. get everybody off to OT and things were fine. Things had kind

22. of settled down. I'd I'd requested staff but never got any. Em so

23. we'd just barried (sic) on which was probably wrong but we just...

24. we never had any choice we just got on with it.

In the form of a report, Emma provides a chronological account describing a very busy and short-staffed ward. Expressions such as 'a lot of problems with staffing and things like that' (L13-14); 'we'd a lot of people boarding out' (L18); 'a lot of things going on basically' (L19); 'never got any' (L22) and 'never had any choice' (L24) are examples of what Pomerantz calls extreme case formulations [26]. When offering a justificatory account, people will need to find a way of accounting for the event. Here, Emma is required to attribute the cause of the suicide to something or someone else in order to determine that she is not to blame. Using the words 'lots' repeatedly help her to assert the strongest case in anticipation of a potentially, nonsympathetic hearing [26]. These extreme case formulations also help to position Emma as a conscientious and hard working nurse who had given her best despite very difficult circumstances.

Emma constructed her account in a more or less chronological and 'factual' manner in order to achieve interactional success and protect her account from being disputed. At times though, too much detail may reduce the success of descriptions or accounts. There is a balance that needs to be reached in order to offer descriptions as acceptable and plausible to the listener in terms of both the credibility of the speaker's account of the account and with the truth claims made within the account. Demonstrating variability, Anna takes a slightly different approach when she orientates to accountability

\section{Anna}

1. From what I remember there was only Emma and myself

2.working that day and we had to get a nursing assistant from

3. another ward to help us out because of our numbers. And it

4. was our usual ... I think it was actually a Tuesday morning

5 . and we were getting everybody organised after breakfast

6. medications ... getting the patients organised for therapies

7. and that particular patient had fifteen minutes time out to

8. go to therapies ... herself ... which she did so. I remember

9. that there had been nothing untoward indicating her mental

10. state that she was depressed or any intention of suicide ...

11. that she was bright ... cheery ... chirpy... attended to her

12. hygiene ... had her breakfast
Anna begins by doing some remembering [27]. Remembering (and forgetting) is not simply a cognitive process [28]; rather, it is a social action, where "people's accounts of the past ... are constructed with regard to particular communicative circumstances". Through this thinking out loud approach Anna implies that her account may not be completely accurate and is dependent upon memory, making available an inference that memory may not always be reliable. In other words she provides a disclaimer for herself 'From what I remember' (L1) and 'I think it was ... (L4). Should the information turn out to be incorrect then the error will be attributed to a fallible memory and outwith Anna's control. The danger in being systematically vague, of course, is that Anna's account could be dismissed as unreliable. Anna orients to this potential difficulty by adding a specific detail, 'Tuesday' (L4) bringing a degree of 'factual' accuracy to her account and would work to restore Anna's credibility [21] if necessary by providing "the essentials to found a particular inference".

This section highlights just how important it is for the nurses to paint a picture right at the start, which will orient to and counter professional accountability concerns that others may have. Thus, none of the details supplied in the scene setting can be viewed as unnecessary or inconsequential. They all perform particular discursive functions. The next section moves on to explore how the nurses orient to the professional activity of risk assessment.

\section{Intuitive and Formal Risk Assessment}

The second part of this sequence (L10-12) involves Anna's assessment concerning the patient as being at risk (or as a risk). Anna lists a number of factors to support the notion that the patient was well, thus not a suicide risk. Drawing on a particular nursing 'interpretive repertoire' [19] Anna addresses three key activities of daily living [29]. This approach to nursing care requires that when a person is in hospital for example, the patient's ability to carry out particular activities is assessed to identify the impact illness has had on them (with the aim of setting 'goals' that will restore the person to a previously 'healthier' state). Anna orients to 'mood' 'personal hygiene' and 'appetite'. The ability to carry out these activities is particularly linked to assessment in psychiatric settings and thus, professional accountability concerns. The feature of interest of course is the significance that when discussing such issues with someone who shares understanding no explanation or further detail will be required. Interpretive repertoires are extremely subtle discursive resources that when illuminated show just how much particular pockets of knowledge or experience can be taken for granted.

\section{Attributing for the Suicide}

Common to both accounts, is the suggestion that it had been a normal morning in the ward, albeit a busy one. Both accounts contrast mitigating factors on the one hand with descriptions of an ordinary day and on the other showing variability in how we can account for the same thing. Here a contrast is made between the normal and the abnormal and the expected with the unexpected. This detail is likely to be clearly recognisable to those who have worked in mental health settings and fits with Potter's observation whereby issues of normality are closely connected to the issue of 
regularity [25]. The main point to note is that immediately before the news that there was something wrong, the speaker left us with the picture of a 'settled' ward. This is quite a common strategy used before introducing the 'unexpected'. It serves again to distance the speaker from the subsequent event [30].

\section{Emma}

30. I'd spoke to the patient that morning and

31. she was fine and she was actually going on pass in the

32. afternoon and she was for discharge the next day.

33. Em she did have a schizophrenic illness though (cleared throat).

Like Anna, Emma also offers her own risk assessment (L30-32). This talk is ordered, detailed and rhetorically very powerful. Providing news that she had spoken to the patient that morning, Emma draws attention to two, commonplace activities, and refutes an implicit suggestion that something had been missed. First, nursing staff are not always able to speak with all patients in the ward, particularly this early in the morning and second, the information about the patient was not provided second hand by another person, e.g. nurse or patient. That Emma had spoken to the patient face to face provides a greater credibility to her assessment of the patient. Unlike Anna's assessment, which was framed around the patient's behaviours, Emma supports her assessment, by indirectly introducing 'others' (L31-32). The information relating to 'going on pass' and 'being discharged' has at least three further actions. First, it aims to show that the patient 'was fine' and so by implication not viewed as at risk of suicide. Next, the multidisciplinary team would have taken the 'management' decisions and so widens the net around those who could share in the responsibility or blame and finally, helps to move agency away from the nurse.

In sum, both accounts report that the patient had not shown any signs of suicidal intent on that morning or by implication, for some time before the event. By identifying that formal and informal assessments had been carried out Emma and Anna are able to counter indirect suggestions that any danger signs were there and had been missed through failing to carry out their professional duties.

\section{Confirmation and Contradiction}

Other supportive devices can be observed in the risk assessment sequences. Emma and Anna use a three-part listing device described by Jefferson [31] 'I'd spoke to the patient that morning and she was fine and she was actually going on pass ... and she was for discharge the next day' (E L30-32). Using this listing device helps to provide a sense of consensus and completeness and, as Jefferson noted, there may be more than 3 parts to the list. To show that 'there had been nothing untoward' and the patient had indeed been fine before going to OT, Anna included 5 reasons, (the patient) was bright, cheery, chirpy; attended to her hygiene; had her breakfast (A L8-12). Speakers use detailed descriptions to manage what Potter $[19,32]$ describes as issues of stake. It is in the nurses' own interests to provide this level of detail in order to strengthen their identity as conscientious nurses. When attending to issues of stake, participants may be orienting to the unspoken, but available inferences may be up for grabs. Listing the absence of any warning signs helps to emphasise the 'ordinary'. The picture of an ordinary day with an 'ordinary' patient, who was 'fine', presents a considerable interactional dilemma as it directly conflicts with the common sense notion that patients who are 'fine' would not be expected to carry out suicide.

Emma recognises that having just supplied information to claim that the patient was not at risk of harming herself, these justifications did not work to explain the subsequent suicide. After a pause, the link to the patient having a schizophrenic illness was made (E L33). Reporting that the patient had a schizophrenic illness is a feature of Emma's report that will carry a special authority. Potter [19] describes this as a category entitlement (p114) because, as a trained nurse, Emma will be expected to possess particular knowledge and understanding that others would not have. Furthermore, the reference to schizophrenia offers an explanation for the subsequent suicide and so Emma provides a reason that may work to exonerate the nurses from potential accusations of 'missing something'. This perception of risk may well conform to the idea that psychotic patients may be at highest risk of suicide when they are well and awaiting discharge. Nonetheless, this highlights something of an issue for the nurses as it contradicts the earlier reports of the patient's 'wellness'.

Contradiction in talk is not an unusual event however: rather, it can be seen as a feature of everyday accounting practices as people will contradict themselves in order to attend to contextual and interactional concerns. Potter and Wetherell illustrate this in their work on racism [20]. They identify how a white New Zealander initially supportive of the idea of teaching Polynesian immigrants appropriate skills, contradicts himself to deal with a locally produced, interactional concern. Exploring contradiction and variability helps to show how accounts like Emma's and Anna's are organised to rebuke unspoken objections (for example, they must have missed something; they should have demanded more help; their assessment of the patient's mental state must have been wrong; if everything was fine why did the patient commit suicide?). Justificatory accounting therefore is crucial for self-identity and more importantly here, for professional accountability.

\section{DISCUSSION}

The nurses' descriptions can be seen to take the form of accounts and accounts can be seen as "culturally embedded forms of mundane talk and are routinely expected whenever conduct falls outside the domain of normative expectations" [33] and are typically made up of descriptions (19). Within the interview and interaction all parties inevitably position themselves as nurses as opposed to say, a women or a sister. As a result, however, their experience of the patient suicide is positioned in relation to particular categories that are available to them as psychiatric nurses. In other words there is a particular world view available which offers them a framework for interpreting the events. This idea of positioning is described by Davies and Harre [34] as:

\footnotetext{
"The discursive process whereby selves are located in conversations as observably and subjectively coherent participants in jointly produced storylines".
} 
The discursive resources drawn upon are seen in everyday interactions and will not be unique to this setting. Orientation to professional accountability was the main theme within the talk. The focus of the analysis therefore, was on the ways accountability was constructed. Discourse analysis has identified both the variability within the constructive abilities and the action orientations of language. In other words, the strategic deployment of the talk was examined to identify the particular actions accomplished. Variability has been shown to be analytically revealing. It helps to identify the variety of discursive strategies people draw on to perform different functions and how these are particularly organised to orientate to different actions.

According to Potter [19] the action being done by descriptions is often subtle and indirect. Usually this is because the event is sensitive and the speaker is at risk of being seen in a bad light. Edwards and Potter describe the features involved with the production of descriptions as a way of managing the 'dilemma of stake' [21]. The dilemma is anything that the speaker says may be discounted by others as a product of the speakers' stake or interest. Thus, the more detail or 'fact' the speaker can provide the more solid, literal and 'objective' the account will be.

Discourse analysis has shown that the way a description or account is constructed is crucial for its interactional success. Detail helps to do two things. First, it helps to build up objectivity and facticity of the accounts. Second, detail also provides the impression of 'being there' by providing certain features that would have been apparent to witnesses $[21,25]$.

This type of accounting seen in the nurses' interviews is often produced when people are explaining actions that are unusual, bizarre or in some way reprehensible [35]. Potter describes these kinds of accounts as being intrinsically interesting because they are such a habitual feature of language use. Accounts can be seen as excuses or justifications and examination of features such as these can illuminate understanding of the causes of action and events or the explanations put forward for them, such as an account of patient suicide $[21,25]$.

As Potter has reported, such discursive strategies can be seen as offensive and defensive rhetorical devices [25]. First, offensive rhetoric works to undermine potential alternative descriptions and second, the use of defensive rhetoric can help to resist discounting or undermining. Potter believes that attention to the use of rhetorical devices can emphasise the relation between a description and an alternative description and the way such relationships may be worked up in argument. In other words, what is emphasised here through the analysis of the nurses accounts are examples of how people can use and alternate between different discursive strategies to add force to their 'side' and make their account more convincing and persuasive to the listener, thus making their account more difficult to question.

Context is another feature that should be acknowledged in the production of any accounts. Here it is important for the interviewer to acknowledge and make visible his/her position within the interaction [36]. In order to analyse these accounts it is important to be aware of the influence the author's background brings to the analysis. As the interviewer was also a psychiatric nurse who had worked alongside both nurses it is clear that all participants orientated towards a shared membership category. Words used within a particular context such as 'pass', 'OT' and 'time-out' illustrated the psychiatric nurses shared knowledge and understandings. This orientation to membership categorisation was reflected by the absence of requests for clarification, definition or explanation of 'psychiatric nurses' talk'.

\section{CONCLUSION}

Discourse analysis has identified how the meaning of patient suicide has been constructed in terms of accountability within the context of the nurses' 'stories'. This orientation to accountability suggests that for these psychiatric nurses accountability is an important issue for them. Indeed, according to the Nursing and Midwifery Council [37]:

\section{"You are personally accountable for your practice. This means that you are answerable for your actions and omissions, regardless of advice from or directions from another professional"}

This statement imports a very strong professional obligation with very little instruction or explanation. Owing to the apparent vagueness of the concept of accountability, particularly for when things go wrong, Dowling et al. [38] report that experienced nurses and consultants become vulnerable to complaints or legal action. Using a fictional case as an illustrative example to show how accountability is contradictory and complex, these authors show how nurses are simultaneously accountable to the trust and the consultant, professionally accountable to the NMC and individually accountable to the patient (and or family/carer). It is not difficult to see how complex and muddied accountability could become for nurses.

Mitchell [39] undertook a qualitative study of how mental health nurses deal with incidents which conflict with their accountability. The critical incidents concerned related to verbal and physical aggression, suicidal behaviour (actual and threatened) and incidents concerning 'lack of support' from both line managers and medical colleagues. The nurses identified 'methods' which helped them deal with issues affecting their accountability, namely: team support, clinical supervision and debriefing. Mitchell also found that 'some nurses remain unsure of their responsibility in relation to their accountability, especially aspects of legal accountability' and the author proposes a systematic programme of education and support achieved by means of effective clinical supervision to address this. In an ethnographic study of practice nurses' accountability, Savage and Moore have also raised concerns about a lack of practitioner clarity over professional and legal accountability [40].

In the present study however, the terms accountability, responsibility, or blame were never uttered, only alluded to. That these nurses do not verbalise their concern in any direct way makes the omissions particularly noteworthy. The findings from this study suggest that nurses' attention to potential accountability issues may actually result in simply serving and reinforcing the dominant professional and political discourse. If nurses unquestioningly accept that in 
their role they "are answerable for (their) actions and omissions, regardless of advice from or directions from another professional" [36] then, accepting 'accountability' may add to their burden. Benson et al. describe how current policies claiming to get rid of a culture of blame to a more open culture "may in fact be perpetuating the former at the expense of the latter" [41]. This can happen by shifting accountability away from the professional body or institution for example and onto the nurse or other care provider.

Perhaps though, the question is arguably not whether nurses accept accountability but whether they internalise expectations regarding suicide, which may be fundamentally unrealistic [5]. Blaming oneself for something, which in the short term could not reasonably have been foreseen (and thus prevented) is clearly psychologically unhealthy. Discourses such as accountability, risk and risk assessment can serve to construct unrealistic expectations, which individuals then internalise. When they later judge themselves against such standards they will inevitably come up wanting. Professional bodies, legislation and guidance persistently support patient autonomy yet we often stop short of holding patients responsible for their own actions, such as suicide.

This study has showed that discourse analysis does not concern itself directly with the cognitive activities of the participants (i.e. remembering or emotional) however, the discursive features and strategies identified through analysis clearly show that these are issues of stake and interest for both participants. Coming to terms with the event of a patient suicide is likely to rely on discursively mastering the competing versions of 'truth'. From a social constructionist perspective, reality is built from and through the use of language, and behaviours and beliefs can be reinforced depending on which version of reality is being played out (and by whom). If speakers become more conscious of the actions accomplished by theirs or others' language deployment, they may be in a position to change their 'talk' or challenge other talk and discourses if viewed as disempowering.

It is has not been the aim of this paper to make generalisations about the particular 'versions of reality' offered by the speakers rather the analysis has revealed how 'facts' and 'objectivity' can be built up in talk and presented in a particular way to accomplish particular actions. Nevertheless, it may well be the case that the discursive strategies deployed here to account for accountability may be the same ones that will be used in other contexts by other people to perform the same sorts of actions.

Nurses that have been involved with a patient suicide may be particularly interested in the revealing nature of applied discourse analysis. This method has the advantage of presenting rich and insightful descriptions of everyday nursing practice. The findings from this study offer nurses who have or have not been involved with patient suicide a chance to reflect on potential issues of accountability relating to their own practices. For nurse managers or policy makers this study has provided some insight into the lasting effects of patient suicide on these nurses. The implications are clear, existing support practices may need reformed and nurses may benefit from a clear support strategy specifically attending to patient suicide. Nurse may also need to engage more in the political and professional discourse and rhetoric that concepts such as accountability rest upon.

The authors would like to express a debt of gratitude to the nurses who put their trust in the researcher and gave up their time to talk about a very painful experience. Their participation in this small study will help to raise awareness of current response to patient suicide, stimulate reflection and further discussion.

\section{REFERENCES}

[1] National Health Service Scotland Information and Statistical Services Division Statistical Publication Notice. 7th August 2009: Suicide statistics 2007, Edinburgh 2008.

[2] News release: Suicide rates vary widely across the UK. Health statistics quarterly. Crown: 2006.

[3] Midence K, Gregory S, Stanley R. The effects of patient suicide on nursing staff. J Clin Nurs 1996; (2): 115-20.

[4] Alexander DA, Klein S, Gray NM, Dewar IG, Eagles JM. Suicide by patients: questionnaire study of its effect on consultant psychiatrists. Br Med J 2000; 320: 1571-4.

[5] Paterson B, Dowding D, Harries C, Cassells C, Morrison R, Niven $\mathrm{K}$. Managing the risk of suicide in acute psychiatric inpatients: a clinical judgement analysis of staff predictions of imminent suicide risk. J Mental Health 2008; 17 (4): 410-23.

[6] Valente SM, Saunders JM. Nurses' grief reactions to a patient's suicide. Perspect Psychiatr Care 2002; 38(1): 5-14.

[7] Bowers L, Gournay K, Duffy D. Suicide and self-harm in inpatient psychiatric units: a national survey of observation policies. J Adv Nurs 2000; 32 (2): 437-44.

[8] National Inquiry. The national confidential inquiry into Suicide and Homicide by People with Mental Illness. UK: The Centre for Suicide Prevention University of Manchester 2006.

[9] Bultema JK. The healing process for the multidisciplinary team; recovering post in-patient suicide. J Psychosoc Nurs Ment Health Serv 1994; 32(2):19-24.

[10] Lacey A. In: The research process in nursing. The research process, $5^{\text {th }}$ ed. Oxford: Blackwell Publishing 2006.

[11] Schegloff EA. "Whose text? Whose context?," Discourse Soc 1997; 8(2): 165-87.

[12] Denzin N K, Lincoln YS. The discipline and practice of qualitative research. $3^{\text {rd }}$ ed. The SAGE handbook of qualitative research. Thousand Oaks: SAGE Publications 2005.

[13] Wetherell M. Identities, groups \& social issues. Open University: Sage Publication Ltd 1996.

[14] Potter J, Wetherell M. Accomplishing attitudes: fact and evaluation in racist discourse. Text 1988; 8: 51-68.

[15] Moir J. Occupational career choice: accounts and contradictions. In: Burman E, Parker I, Eds. Discourse analytic research: repertoires and readings of texts in action. London: Routledge 2000.

[16] Harper D. Tablet talk and depot discourse: discourse analysis and psychiatric medication. In: Willig C, Ed. Applied discourse analysis: social and psychological interventions. Buckingham. Philadelphia: Open University Press 1999.

[17] Robertson M. A discourse analysis of shared decision making in primary care consultations. Unpublished $\mathrm{PhD}$ Thesis. University of Dundee 2004.

[18] Robertson M, Moir J, Skelton J, Dowell J, Cowan S. When the business of sharing treatment decisions is not the same as shared decision-making?: a discourse analysis of decision sharing in general practice. Health 2009 (in press).

[19] Potter J. Wetherell M. Discourse and social psychology: beyond attitudes and behaviour. London: Sage Publications 1987.

[20] Wetherell M, Potter J. Mapping the language of racism: discourse and the legitimation of exploitation. USA: Columbia University Press 1992.

[21] Edwards D, Potter J. Discursive psychology. London. Newbury Park; New Delhi: Sage Publications 2000.

[22] Ashmore M, Reed D. Innocence and Nostalgia in conversation analysis: the dynamic relations of tape and transcript. FQS 2000; 1(3): Art 3.

[23] Widdicombe S. Autobiography and change: rhetoric and authenticity of 'Gothic' style. In: Burman E, Parker I, Eds. 
Discourse analytic research: repertoires and readings of texts in action. London: Routledge 1993.

[24] Dixon-Woods M, Suokas A, Pitchforth E, Tarrant C. An ethnographic study of classifying and accounting for risk at the sharp end of medical wards. Soc Sci Med 2009; 63: 362-9.

[25] Potter J. Representing reality. London: Sage Publications 2000.

[26] Pomerantz M. Extreme case formulations a way of legitimizing claims. Human Studies 1986; 9: 219-29.

[27] Wooffitt RC. Analysing accounts. In: Potter J, Ed. Representing reality London: Sage Publications 2000.

[28] Middleton D, Edwards D. Collective remembering. Inquiries in Social Construction. London: Sage Publications 1990.

[29] Roper N, Logan W,Tierney A. The elements of nursing. Churchill Livingstone 1980.

[30] Goffman E. Footing. 1992. In: Potter J, Ed. Representing reality. London: Sage Publications 2000.

[31] Jefferson, G. List construction as a task and resource. In: Potter J, Eds. Representing reality. London: Sage Publications 2000.

[32] Gilbert GN, Mulkey M. In, Potter J, Ed. Opening Pandora's box: a sociological analysis of scientists' discourse: representing reality. London: Sage Publications 2000.

[33] Arribas-Ayllon M, Sarangi S, Clarke A. Managing selfresponsibility through other-oriented blame: family accounts of genetic testing. Soc Sci Med 2008; 66(7): 1521-32.
[34] Davies B, Harré R. 'Positioning: The social construction of selves'. J Theor Soc Behav 1990; 20: 43-63.

[35] Scott MB, Lyman SM. Accounts. In Potter J, Ed. Representing reality. London: Sage Publications 2000.

[36] Wetherell M, Taylor S , Yates SJ. Discourse as Data. London, Thousand Oaks, New Delhi: Sage Publications 2001.

[37] A-Z Advice Sheet. Accountability. Available from http://www. positive-options.com/news/downloads/NMC_-_Accountability_A$\mathrm{Z}$ advice sheet - 2006.pdf. [Accessed December 2008].

[38] Dowling S, Martin R, Skidmore P, Doyal L, Cameron A, Lloyd S. Nurses taking on junior doctor's work: a confusion of accountability. Br Med J 1996; 312: 1211- 4.

[39] Mitchell G J. A qualitative study exploring how qualified mental health nurses deal with incidents that conflict with their accountability. J Psychiatr Ment Health Nurs 2001; 8: 241 - 8.

[40] Savage J, Moore L. Interpreting accountability: an ethnographic study of practice nurses, accountability and multidisciplinary team decision making in the context of clinical governance. RCN Institute. London: Royal College of Nursing 2004.

[41] Benson A, Secker J, Balfe E, Lipsedge M, Robinson S, Walker J. Discourses of blame: accounting for aggression and violence on an acute mental health inpatient unit. Soc Sci Med 2003; 57: 917-26.

(C) Robertson et al.; Licensee Bentham Open.

This is an open access article licensed under the terms of the Creative Commons Attribution Non-Commercial License (http://creativecommons.org/licenses/by$\mathrm{nc} / 3.0 /$ ) which permits unrestricted, non-commercial use, distribution and reproduction in any medium, provided the work is properly cited. 